\title{
Embargos e Interdições em Canteiros de Obras: Uma Perspectiva Sistêmica'
}

\author{
Tarcisio Abreu Saurin
}

\section{Introdução}

As inspeções conduzidas por órgãos governamentais têm papel importante na garantia do atendimento à legislação de segurança e saúde no trabalho (SST) em canteiros de obras. De fato, pressões externas são normalmente necessárias quando se trata de requisitos não exigidos pelo usuário final, tais como aqueles ligados à SST.

Contudo, não há evidências conclusivas sobre os impactos das inspeções na redução dos índices de acidentes. Em parte, isso se deve a dificuldades metodológicas de isolar o efeito de inspeções. Um dos principais estudos quantitativos acerca do tema foi realizado por Levine et al. (2012) em uma grande amostra de empresas de vários setores nos EUA. As conclusões apontaram que as inspeções reduziram as taxas de acidentes, com nenhuma evidência de impactos negativos em termos de redução de empregos, vendas ou sobrevivência da empresa.

Embora estudos quantitativos possam fornecer generalizações estatísticas sobre a eficácia das inspeções, isso não significa que canteiros de obras individuais sejam imunes a uma mistura de impactos desejados e indesejados. Nesse sentido, o Pensamento Sistêmico (PS, systems thinking) permite uma análise mais abrangente

1 Este capítulo é uma versão condensada e adaptada de uma publicação em um periódico internacional: Saurin, T.A. 2016. Safety inspections in construction sites: a systems thinking perspective. Accident Analysis and Prevention, 93, 240-250. 
das inspeções de SST, ajudando a esclarecer os seus efeitos em contextos específicos. Neste capítulo, é discutido como o PS pode contribuir para uma melhor compreensão dos impactos das inspeções, bem como dos mecanismos que levam aos impactos.

A discussão é realizada com base em estudos de caso de canteiros de obras que foram interditados ou embargados por uma inspetoria governamental de SST. O autor esteve envolvido como observador participante nestes estudos de caso, que ocorreram ao longo de seis anos.

\section{Método de Pesquisa}

As inspeções foram analisadas segundo a perspectiva de quatro atributos do PS identificados por Wilson (2014). O primeiro atributo é a preocupação com o contexto, que implica em identificar fatores que influenciam o comportamento dos agentes, acarretando em dificuldades e oportunidades. A visão holística deve ser valorizada, buscando interações e mecanismos causais que estão distantes, no tempo e no espaço, das ações e decisões dos agentes (SKYTTNER, 2005). O segundo atributo é o reconhecimento das interações, o qual se contrapõe à ênfase do pensamento linear na compreensão apenas das partes. As interações possuem características peculiares em sistemas complexos, tais como a não proporcionalidade entre causas e efeitos, natureza dinâmica, feedback loops e incerteza (CILLIERS, 1998).

O reconhecimento de fenômenos emergentes é o terceiro atributo. Tais fenômenos são manifestações da variabilidade inesperada, surgindo das interações entre os agentes em vez de algum controle centralizado. Fenômenos emergentes têm propriedades novas, que não existem nos elementos individuais que interagem (CILLIERS, 1998). O quarto atributo diz respeito à consideração de diversas perspectivas. Os agentes de um sistema diferem entre si segundo diversas categorias, tais como níveis hierárquicos, divisão de tarefas, nível de especialização. Embora a diversidade crie dificuldades de coordenação, ela contribui para a tomada de melhores decisões (DEKKER, 2011).

Foram realizados 13 estudos de caso em canteiros de obras que estavam sob a jurisdição de uma inspetoria do trabalho com longa tradição de ser ativa, exigente e possuir inspetores (denominados auditores fiscais do trabalho) qualificados tecnicamente. Segundo dados coletados pela inspetoria de 2003 a 2009 (BRASIL, 2010), 46,9\% dos embargos e interdições ocorreram na construção civil, enquanto este setor foi responsável por $19 \%$ dos acidentes fatais no mesmo período.

As fontes de dados foram as mesmas em todos os casos, envolvendo: (i) observação participante; (ii) observação direta; (iii) análise de relatórios de interdição e embargo preparados pelos inspetores. Enquanto os dados provenientes dessas fontes 
foram reunidos ao longo dos seis anos. Em 2015, duas entrevistas semiestruturadas foram realizadas com dois inspetores. Os entrevistados foram escolhidos devido a sua experiência (> 20 anos no serviço de inspeção) e disponibilidade. Cada entrevista durou cerca de 1,5 hora, com foco na compreensão das atividades da inspetoria, bem como na visão dos inspetores acerca dos pontos fortes e fracos do processo de auditoria em si.

A observação participante foi a principal fonte de dados, uma vez que o pesquisador colaborou com as equipes de gerenciamento das obras na concepção e avaliação de medidas corretivas implantadas como resultado das inspeções. A oportunidade para a observação participante surgiu do fato de que, como resultado das inspeções, as construtoras têm recorrido a universidades em busca de assistência técnica. Assim, o pesquisador participou de diversas reuniões com as equipes gerenciais (cerca de 65 horas ou 5 horas por estudo de caso), além de uma reunião na sede da inspetoria (1 hora), em que os gerentes de um dos canteiros solicitaram esclarecimentos sobre as razões para a interdição e medidas de controle previstas.

As observações diretas permitiram verificar, nas próprias obras, as deficiências apontadas nos relatórios de interdição e embargo. Cerca de 80 horas de observações diretas foram realizadas (aproximadamente 6 horas por estudo de caso), variando de 2 a 10 horas por estudo.

Em relação à análise de documentos, os relatórios de interdição foram uma fonte de dados valiosa, visto que estes eram documentos detalhados, com a perspectiva dos inspetores sobre os perigos e como eles deveriam ser controlados.

\section{Resultados}

\subsection{Características das Interdições e Embargos Analisados}

A Tabela 1 apresenta as principais características dos estudos de caso em ordem cronológica, desde a paralisação mais recente até a mais antiga. As treze interdições e embargos investigados ocorreram ao longo de seis anos em doze diferentes canteiros. Apenas quatro inspetores diferentes estavam envolvidos nestes casos (20\% do total da inspetoria local) e a duração média das paralisações foi de 4,5 meses. Em sete casos $(53,8 \%)$, as construtoras recorreram ao sistema judiciário na tentativa de acabar com a interdição ou embargo. Os casos envolvendo litígios tiveram paralisações mais longas (5,7 meses) em comparação aos casos em que foram usados apenas os mecanismos administrativos regulares (3,2 meses). As construtoras comumente faziam duas rodadas de defesa administrativa antes de recorrer à opção judicial. 
Tabela 1 - Características das interdições e embargos analisados.

\begin{tabular}{|c|c|c|c|}
\hline $\begin{array}{l}\text { Propósito da } \\
\text { construção }\end{array}$ & Principais objetos de interdição e embargo & $\begin{array}{l}\text { Duração da } \\
\text { paralisação }\end{array}$ & $\begin{array}{l}\text { Disputa } \\
\text { legal? }\end{array}$ \\
\hline $\begin{array}{l}\text { (1) Habitação de } \\
\text { interesse social }\end{array}$ & $\begin{array}{l}\text { Proteções periféricas, falta de programa de } \\
\text { gerenciamento de estresse térmico, levantamento } \\
\text { manual de pesos, falta de proteção coletiva junto } \\
\text { ao parapeito de janelas }\end{array}$ & 3 meses & Não \\
\hline $\begin{array}{l}\text { (2) Ampliação } \\
\text { de um shopping } \\
\text { center }\end{array}$ & $\begin{array}{l}\text { Montagem de estruturas de concreto pré- } \\
\text { fabricado, montagem de estruturas metálicas }\end{array}$ & 6 meses & Sim \\
\hline $\begin{array}{l}\text { (3) Prédio } \\
\text { residencial }\end{array}$ & $\begin{array}{l}\text { Proteções periféricas, linhas de vida, plataformas } \\
\text { de proteção, transporte manual de cargas pesadas }\end{array}$ & 6 meses & Sim \\
\hline $\begin{array}{l}\text { (4) Ampliação } \\
\text { de um shopping } \\
\text { center }\end{array}$ & $\begin{array}{l}\text { Escavações, trincheiras, fundações, falta de } \\
\text { programa de gerenciamento de estresse térmico } \\
\text { *Mesmo canteiro de obras do item 2, que foi } \\
\text { interditado duas vezes pelo mesmo inspetor em } \\
\text { diferentes etapas da construção }\end{array}$ & 3 meses & Não \\
\hline $\begin{array}{l}\text { (5) Prédio } \\
\text { comercial }\end{array}$ & Linhas de vida, escavações, serra circular & 2 meses & Não \\
\hline $\begin{array}{l}\text { (6) Prédio } \\
\text { comercial }\end{array}$ & $\begin{array}{l}\text { Linhas de vida, proteções periféricas, falta de } \\
\text { programa de gerenciamento de estresse térmico }\end{array}$ & 5 meses & Sim \\
\hline $\begin{array}{l}\text { (7) Prédio } \\
\text { residencial }\end{array}$ & $\begin{array}{l}\text { Mesmos problemas que o canteiro } 2 \text {, além de } \\
\text { elevadores para o transporte de materiais, falta de } \\
\text { programa de gerenciamento de estresse térmico }\end{array}$ & 8 meses & Sim \\
\hline $\begin{array}{l}\text { (8) Prédio } \\
\text { comercial }\end{array}$ & $\begin{array}{l}\text { Proteções periféricas, elevadores para o transporte } \\
\text { de materiais }\end{array}$ & 5 meses & Sim \\
\hline $\begin{array}{l}\text { (9) Habitação de } \\
\text { interesse social }\end{array}$ & $\begin{array}{l}\text { Proteções periféricas, circulação de veículos } \\
\text { pesados dentro do canteiro de obras }\end{array}$ & 4 meses & Não \\
\hline $\begin{array}{l}\text { (10) Prédio } \\
\text { residencial }\end{array}$ & $\begin{array}{l}\text { Escavações, betoneiras, circulação de veículos } \\
\text { pesados dentro do canteiro, falta de programa de } \\
\text { gerenciamento de estresse térmico }\end{array}$ & 6 meses & Sim \\
\hline $\begin{array}{l}\text { (11) Prédio para } \\
\text { estacionamentos }\end{array}$ & $\begin{array}{l}\text { Proteções periféricas e linhas de vida *Mesma } \\
\text { empresa do canteiro 1, mas obra diferente }\end{array}$ & 4 meses & Não \\
\hline $\begin{array}{l}\text { (12) Prédio } \\
\text { residencial }\end{array}$ & $\begin{array}{l}\text { Andaimes suspensos, linhas de vida e proteções } \\
\text { periféricas }\end{array}$ & 3 meses & Não \\
\hline $\begin{array}{l}\text { (13) Prédio } \\
\text { residencial }\end{array}$ & $\begin{array}{l}\text { Andaimes suspensos * Mesma empresa do } \\
\text { canteiro 10, mas obra diferente }\end{array}$ & 4 meses & Sim \\
\hline
\end{tabular}

Com a exceção dos canteiros 1 e 8 (habitações de interesse social), os demais estavam localizados em áreas urbanas centrais. As obras eram relativamente grandes, 
tendo cerca de 100 trabalhadores no pico (obra 8) até 500 trabalhadores (obra 2). Não foram obtidos dados confiáveis para confirmar se a ênfase em grandes projetos era válida para todo o universo das inspeções. Caso fosse confirmada, tal ênfase estaria em contraste com estudos recentes na mesma região, os quais concluíram que obras menores tinham um nível muito mais baixo de conformidade com os regulamentos de SST (20\% contra 65\%) em comparação aos maiores (COSTELLA et al., 2014). Resultados similares têm sido obtidos em outros países (SINCLAIR; CUNNINGHAM, 2014).

A força de trabalho em todos os canteiros era em grande parte terceirizada (mais de $90 \%$ ) e as tecnologias eram típicas do setor de construção de edifícios residenciais e comerciais no Brasil: fôrmas de madeira montadas no local, estrutura de concreto armado e alvenaria com blocos cerâmicos ou de concreto. Tais tecnologias têm caráter artesanal e envolvem uso intensivo de mão de obra, sendo associadas a taxas de acidentes mais elevadas em comparação à construção industrializada (RUBIOROMERO et al., 2014).

\subsection{Análise dos Estudos de Caso sob o Ponto de Vista do Pensamento Sistêmico}

\subsubsection{Preocupação com o Contexto}

O conteúdo dos relatórios de inspeção indicou que os auditores tinham visão holística em termos de perigos antecipados pela legislação, uma vez que eles apontaram uma ampla gama de situações inseguras. No entanto, as práticas de gestão da segurança não costumavam ser objeto das inspeções, o que reflete a ênfase das normas brasileiras nas proteções físicas. Deste modo, as causas raízes dos riscos, que eram distantes no tempo e espaço em relação aos trabalhos na obra, não eram levadas em conta. Um dos inspetores entrevistados relatou frustração com o fato de que as mesmas empresas são notificadas várias vezes pelos mesmos problemas, em diferentes obras.

Um exemplo que ilustra problemas repetitivos refere-se às grandes diferenças entre como as proteções coletivas são imaginadas em projeto e como são implantadas na prática. A alta incidência dessas diferenças, em todos os estudos de caso, sugere que as causas raízes não estão ligadas a comportamentos individuais dos gestores e trabalhadores. Contudo, as inspeções limitavam-se a apontar as não conformidades, enquanto a gerência das obras costumava se restringir a correções de curto prazo, que muitas vezes implicavam em alterar o projeto para torná-lo aderente ao que estava em uso, em vez do contrário. Esse achado também sugere que, assim como ocorre em outras áreas do projeto das edificações, um "projeto como construído" das proteções coletivas pode ser pertinente. Com base nos dados coletados, as causas das diferenças entre projeto e prática podem ser: 
- O fato dos projetistas de proteções coletivas não serem contratados para fornecer assistência durante a fase de construção, o que aumenta a probabilidade de má interpretação do projeto;

- A falta de participação dos trabalhadores no projeto das proteções coletivas, o que é tanto um resultado do fator anterior como de práticas comuns no setor, que costuma valorizar pouco a participação dos trabalhadores;

- Uma cultura generalizada de "segurança baseada em papel", o que significa que a ênfase é colocada na necessidade de ter projetos e documentações apenas para fins legais. Assim como os anteriores, esse problema decorre de outros de natureza setorial, tal como o predomínio de contratos que enfatizam penalidades legais em detrimento do colaborativo entre as partes contratantes (SAKAL, 2005).

\subsubsection{Consideração de Diversas Perspectivas na Tomada de Decisões}

A necessidade de levar diversas perspectivas em conta ao avaliar riscos e propor medidas de controle parecia ser raramente utilizada pelos inspetores. As observações participantes e relatórios de inspeções indicaram que havia pouco espaço para "segundas histórias" e os inspetores usavam sua autoridade para decidir o que contava como risco iminente e grave. A diferença entre as perspectivas dos inspetores e gestores parecia ser ampla e difícil de ser conciliada. Em um estudo anterior na mesma região (ROCHA, 2011), os pontos de vista dos inspetores e os gerentes de obras foram substancialmente diferentes acerca das razões para as paralisações e as estratégias para reduzir a sua duração e frequência. Uma diferença semelhante nas percepções foi encontrada na África do Sul, onde, assim como no Brasil, cada uma das partes enfatizava as falhas da outra (GEMINIANI et al., 2013). Por exemplo, os construtores salientaram a falta de critérios harmonizados entre os inspetores, enquanto os responsáveis pela fiscalização enfatizavam que as empresas não tinham uma cultura de segurança.

Nos estudos de caso, a desconfiança mútua decorre de uma longa história de relações conflituosas, bem como de uma imagem negativa da indústria da construção como um todo - por exemplo, altas taxas de acidentes, más condições de trabalho e uma força de trabalho mal remunerada. Os sistemas complexos têm uma história pregressa que impacta a forma como os processos são gerenciados no presente (CILLIERS, 1998). O ambiente atual de processos judiciais pode ser interpretado como o pico de um passado de relações ruins, indicando um caminho evolutivo para sistemas similares.

Legislações altamente prescritivas também contribuem para as perspectivas conflitantes. Por exemplo, no estudo de caso 2, o inspetor exigiu que a montagem de treliças metálicas fosse feita a partir de um andaime, como prescrito pela NR-18 - 
Condições e meio ambiente do trabalho na indústria da construção. No entanto, o empreiteiro usava plataformas de transporte aéreo, o que permitia processos de trabalho mais flexíveis. Seguindo estritamente a norma, o inspetor focou em soluções no lugar de riscos a serem controlados.

Em geral, as observações participantes indicaram que, ao longo do tempo, a perspectiva dos inspetores foi adotada pelas construtoras, em termos da definição do que conta como risco inaceitável e medidas de controle adequadas. Isso está de acordo com a noção de que o nível de risco é tanto uma construção social como uma realidade objetiva (SLOVIC, 2001). Além disso, esse cenário estabeleceu padrões locais sobre o que é seguro ou não, embora o significado de "local" em tais casos possa ser restrito a uma obra ou empresa específica. Uma queixa frequente dos empreiteiros envolvidos nos estudos de caso era que eles tinham uma desvantagem competitiva em relação a outros empreendimentos que não foram submetidos a inspeções e que continuavam utilizando práticas de segurança menos exigentes.

A falta de consideração de diversas perspectivas também pode decorrer da "síndrome de prima donna". Prima donnas são profissionais reconhecidos pela sua competência técnica, assertividade e autoconfiança, embora possam ter insensibilidade para metas organizacionais maiores e dificuldades de trabalhar para alguém ou fazer parte de uma equipe (GIRARD, 2005). Dekker (2014) discute a psicologia de prima donnas, a qual ele associa com senso de direitos superiores e narcisismo. Embora essa pesquisa não tenha realizado uma avaliação desta "síndrome", que é promovida por um conjunto de fatores e não apenas por traços de personalidade (DEKKER, 2014), alguns elementos sugerem que pode ser útil investigar tal perfil em novos estudos. Por exemplo, os quatro inspetores envolvidos nos estudos de caso correspondem a apenas $20 \%$ de toda a equipe da inspetoria, e o mais exigente deles é amplamente considerado pelos empreiteiros como muito inteligente e ao mesmo tempo insensível a pontos de vista alternativos.

\subsubsection{Reconhecimento de Interações}

Em termos de reconhecimento de interações, as inspeções de segurança eram limitadas. O foco dos inspetores era encontrar "partes" danificadas, muitas vezes em um sentido literal. Assim, a preocupação com a qualidade de equipamentos, como correias, guindastes, guarda-corpos e elevadores era frequente. Testes laboratoriais eram muitas vezes solicitados como parte das inspeções. Contudo, a literatura de gestão da segurança tem indicado que partes confiáveis não implicam, necessariamente, em um sistema seguro e confiável (LEVENSON, 2011).

Conforme percepção de representantes das construtoras, o foco em partes físicas era devido a uma intenção tácita de desencorajar o uso de tecnologias que os inspetores consideravam inerentemente inseguras. Dois exemplos (Figura 1) estão relacionados ao uso de linhas de vida horizontais e plataformas de proteção. A intenção das inspeções 
era que tais tecnologias fossem substituídas por andaimes fachadeiros ou redes que, em princípio, reduziriam a necessidade de equipamentos de proteção individual.
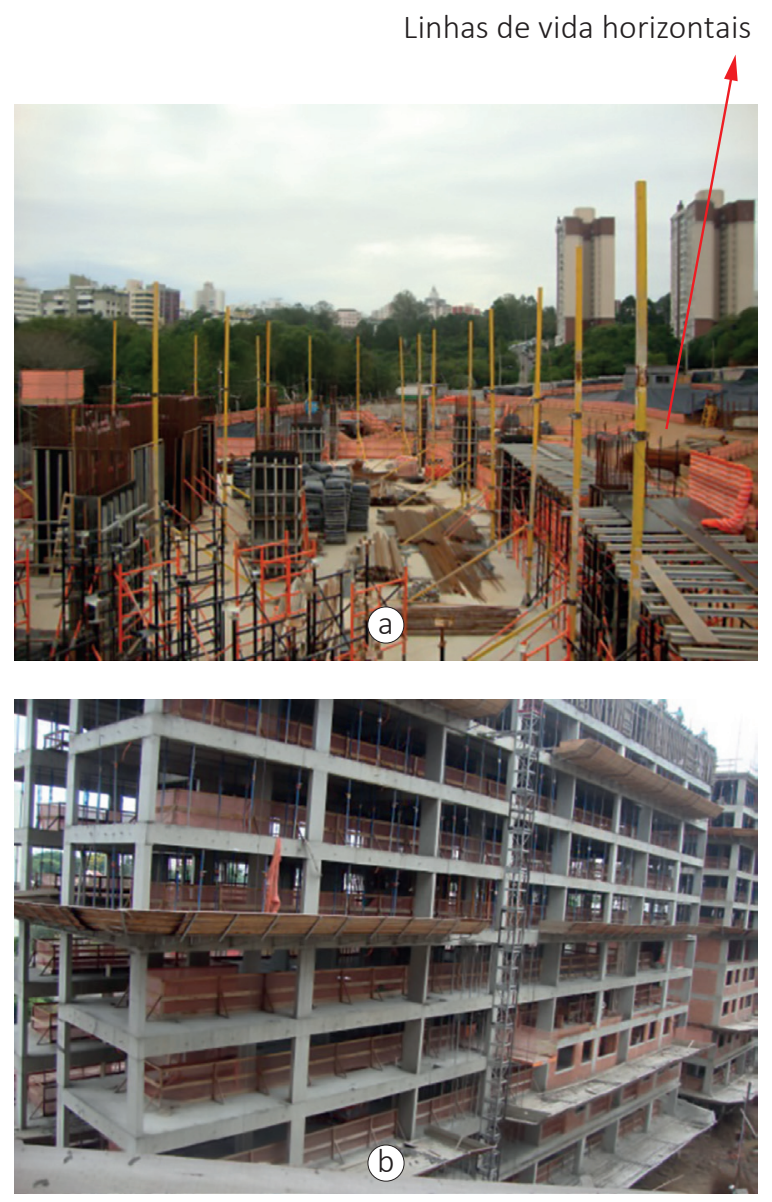

Figura 1 - a) linhas de vida horizontais entre os montantes verticais; b) plataformas para recolher restos de materiais.

De um lado, a busca por partes danificadas é necessária, visto que falhas em equipamentos críticos podem ter efeitos catastróficos e imediatos. Goh e Wang (2015) analisaram 11 projetos de linhas de vida horizontais em Singapura e concluíram que todos eles eram inadequados, proporcionando uma falsa sensação de segurança aos usuários. Em tais casos, a perspectiva sistêmica é menos relevante e uma sequência linear, com claras relações de causa e efeito, pode fornecer uma explicação satisfatória dos eventos que levam a um acidente (PERROW, 1984). 
De outro lado, a supervalorização da busca por partes danificadas tende a negligenciar outros tipos de acidentes que envolvem interações entre partes que isoladamente são confiáveis. Estes são descritos como acidentes sistêmicos por Perrow (1984). Em alguns dos estudos de caso, o pesquisador tomou conhecimento de acidentes que não tinham relação direta com as atividades interditadas ou que tiveram, como fatores contribuintes, mudanças na logística de operações da obra, as quais foram desencadeadas pelas próprias interdições.

\subsubsection{Identificação de Fenômenos Emergentes}

Os resultados apontaram que as próprias inspeções criavam as condições para fenômenos emergentes, caracterizados por consequências não antecipadas e não completamente passíveis de controle. De um lado, fenômenos emergentes desejáveis resultaram das inspeções, tais como inovações incrementais na gestão da segurança. Dois exemplos podem ser mencionados:

- Interdições frequentes devidas à falta de programas de gerenciamento de estresse térmico levaram as construtoras a realizar medições de temperaturas em vários canteiros de obras. Com base nos dados, regimes de trabalhodescanso foram implantados, a partir de certos níveis de temperatura. Essa prática é consistente com a recomendação para a concepção de práticas de gestão de estresse térmico que reflitam as condições climáticas locais (ROWLINSON et al., 2014).

- Devido à pressão dos inspetores, as plataformas ilustradas na Figura 1 têm sido gradualmente removidas dos canteiros de obras locais, sendo substituídas por andaimes fachadeiros ou redes. Como limitação, o pesquisador observou que as inovações mencionadas e outras similares são por vezes limitadas a um protótipo construído apenas para satisfazer os inspetores e acabar com a paralisação. Em tais casos, a gerência da obra, e possivelmente os inspetores, não acreditavam que a solução era de fato viável.

De outro lado, alguns fenômenos emergentes decorrentes das inspeções podem ser prejudiciais para a segurança. Os dois auditores entrevistados não puderam facilmente pensar em qualquer efeito desse tipo, o que é uma demonstração do valor do PS, uma vez que oferece uma nova perspectiva. Um dos efeitos negativos identificados refere-se aos impactos das interdições nos prazos e custos das obras. Tais impactos criam grandes pressões por eficiência quando os trabalhos são reiniciados, o que é prejudicial para a segurança (HAN et al., 2014). Por exemplo, no canteiro 7 (8 meses de interdição), vários clientes registraram ações judiciais contra a construtora, reivindicando compensações pelo atraso. Por sua vez, a construtora ingressou com uma ação judicial contra o governo federal, exigindo compensação financeira para as suas próprias perdas. 
Como outro impacto negativo, muitos trabalhadores buscam outros empregos informais durante as interdições. Tais empregos podem implicar trabalho em condições piores, indo contra o principal objetivo das paralisações. Em particular, a busca por empregos informais acontece quando o subcontratado não tem outra obra para transferir os trabalhadores, situação que é agravada quando o subcontratado não é pago pelo contratante principal, enquanto o canteiro de obras está embargado. Uma vez que subempreiteiros são muitas vezes pequenas empresas com recursos técnicos e financeiros limitados, paralisações longas ameaçam a sobrevivência da empresa.

Sendo ou não a paralisação longa, um fenômeno emergente observado em todos os estudos de caso foi o aparente aumento do nível de estresse entre os gestores. Relatos sugerindo tal aumento eram comuns (por exemplo, "devemos desistir de trabalhar na construção" - subempreiteiro envolvido no canteiro 1, "eu fiquei no escritório até de madrugada para organizar a papelada" - engenheiro de segurança do canteiro 2).

Em geral, os impactos negativos das inspeções podem ser interpretados como uma forma de perda institucional na indústria da construção, que em si é um fenômeno emergente. Esse tipo de perda refere-se a "sistemas institucionais, disposições estruturais e pressupostos cognitivos que apoiam e incentivam atividades desnecessárias na construção" (SARHAN et al., 2014). Os efeitos indesejados dos longos períodos de obras paralisadas podem até mesmo contribuir para a corrupção, que é uma reconhecida fonte de perdas na indústria da construção, em nível nacional e internacional.

\section{Conclusões}

O pensamento sistêmico revelou-se útil para a identificação de benefícios e oportunidades para a melhoria das inspeções. Inicialmente, cabe salientar o papel dos métodos de coleta de dados, que podem permitir análises similares em contextos de inspeções em outras regiões. A observação participante expôs o pesquisador ao complexo contexto real das inspeções. A diversidade de perspectivas foi levada em conta pelo uso de múltiplas fontes de dados, produzidos pelos inspetores (por exemplo, relatórios e entrevistas) e pela equipe gerencial das obras (por exemplo, reuniões para tomar decisões decorrentes dos embargos). O relativo grande número de estudos de caso (13) e o longo período de pesquisa (6 anos) facilitou a identificação de fenômenos emergentes, que se desenvolvem lentamente e muitas vezes ficam invisíveis para participantes internos ao sistema.

Além disso, os resultados indicaram que o pensamento sistêmico, quando aplicado às inspeções de segurança, pode ter foco nos seguintes objetivos (em itálico e negrito na Figura 2): (1) identificação dos agentes envolvidos no sistema associado às inspeções - um reprojeto deste sistema deve considerar explicitamente o papel de cada um destes agentes; (2) identificação de dificuldades e oportunidades 


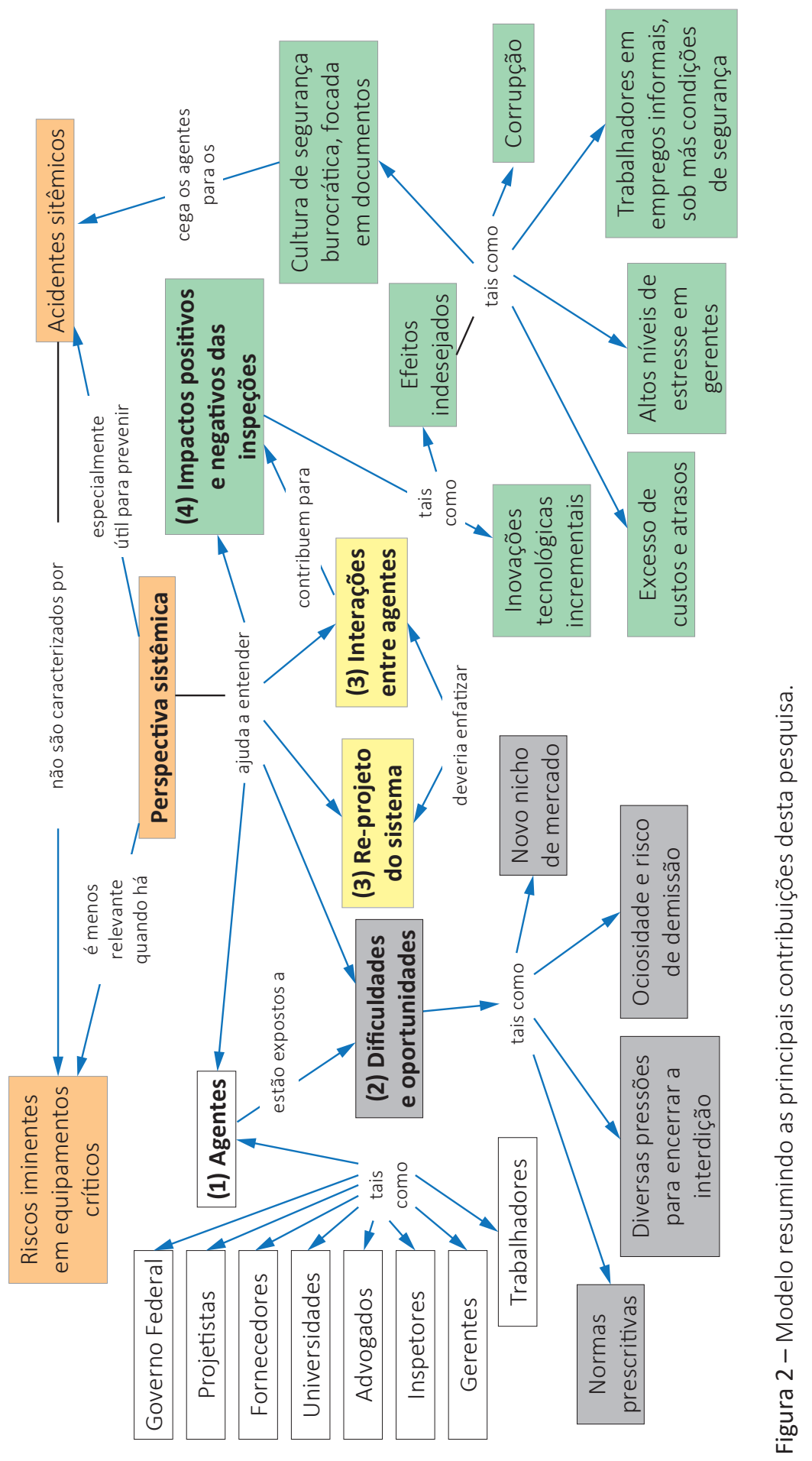


que orientam ações, decisões e interações entre os agentes; (3) identificação de interações entre os agentes, bem como recomendações para influenciar as interações, enfatizando o controle das causas raízes das deficiências detectadas pelos inspetores; (4) identificação dos impactos positivos e negativos das interações. Esses objetivos podem ser associados com os quatro atributos do pensamento sistêmico: (1) diversidade de perspectivas; (2) preocupação com o contexto; (3) interações; (4) fenômenos emergentes.

Embora este estudo tenha sido realizado apenas em uma região do Brasil, os resultados podem ser úteis para outras regiões e países com contextos similares, tais como: normas prescritivas de SST; uma história de relações conflitantes entre construtoras e órgãos de inspetoria; a falta de certificações de terceira parte para equipamentos de proteção coletiva; o baixo uso de tecnologias de construção industrializada, já que a pressão dos inspetores pode ser maior para a modernização. É provável que esse último fator seja mais presente nos países em desenvolvimento, nos quais tende a existir uma tensão entre a necessidade de tecnologias mais seguras e incentivos governamentais (por exemplo, impostos mais baixos) para o uso de métodos artesanais que empreguem mais trabalhadores.

\section{Referências}

BRASIL. Ministério do Trabalho e Emprego. Embargo e interdição: instrumentos de preservação da vida e saúde dos trabalhadores. A experiência da seção de segurança e saúde no trabalho - SEGUR-RS, Porto Alegre. 2010.

CILLIERS, P. Complexity and Postmodernism: Understanding Complex Systems. Routledge, London. 1998.

COSTELLA, M.F.; JUNGES, F.C.; PILZ, S.E. Avaliação do cumprimento da NR-18 em função do porte de obra residencial e proposta de lista de verificação da NR-18 - Ambiente Construído, v. 14, n. 3, p. 87-102. 2014.

DEKKER, S. Deferring to expertise versus the prima donna syndrome: a manager's dilemma. Cognition, Technology and Work, v. 16, p. 541-548. 2014.

DEKKER, S. Drift into failure: from hunting broken components to understanding complex systems. Ashgate, London. 2011.

GEMINIANI, F.; SMALLWOOD, J.; FEE, S. A comparative analysis between contractors' and inspectors' perceptions of the department of labour occupational health and safety inspectorate relative to South African construction. Safety Science, v. 53, p. 186-192. 2013.

GIRARD, N.J. Dealing with perioperative prima donnas in your OR. AORN J. v. 82, n. 2, p. 187-189. 2005. 
$\mathrm{GOH}, \mathrm{Y}$.; WANG, Q. Investigating the adequacy of horizontal lifeline system design through case studies from Singapore. Journal of Construction Engineering and Management, v. 141, n. 7. 2015. DOI: 10.1061/(ASCE)CO.1943-7862.0000989.

HAN, S.; LEEC, S.; MOHAMED, Y.; PENA-MORA, F. Toward an understanding of the impact of production pressure on safety performance in construction operations. Accident Analysis and Prevention, v. 68, p. 106-116. 2014.

LEVESON, N. Applying systems thinking to analyze and learn from events. Safety Science, v. 49, p. 55-64. 2011.

LEVINE, D.; TOFFEL, M.; JOHNSON, M. Randomized government safety inspections reduce worker injuries with no detectable job loss. Science, v. 336, p. 907-911. 2012.

PERROW, C. Normal Accidents: Living with High-Risk Technologies. Princeton University Press, Princeton. 1984.

ROCHA, E. Avaliação de embargos e interdições na construção civil: estudo de caso de uma construtora e incorporadora de Porto Alegre. Trabalho de Conclusão de Curso de Graduação em Engenharia Civil, UFRGS, Porto Alegre. 2011.

ROWLINSON, S.; YUNYANJIA, A.; LI, B.; CHUANJINGJU, C. Management of climatic heat stress risk in construction: A review of practices, methodologies, and future research. Accident Analysis and Prevention, v. 66, p. 187-198. 2014.

RUBIO-ROMERO, J.C.; SUÁREZ-CEBADOR, M.; ABAD, J. Modeling injury rates as a function of industrialized versus on-site construction techniques. Accident Analysis and Prevention, v. 66, p. 8-14. 2014.

SAKAL, M.W. Project alliancing: a relational contracting mechanism for dynamic projects. Lean Construction Journal, v. 2, n. 1, p. 67-79. 2005.

SARHAN, S.; PASQUIRE, C.; KING, A. Institutional waste within the construction industry: an outline. Proceedings of the 22. Annual Conference of the International Group for Lean Construction, p. 895-906. Oslo, Akademika Forlag. 2014.

SINCLAIR, R.; CUNNINGHAM, T. Safety activities in small businesses. Safety Science, v. 64, p. 32-38. 2014.

SKYTTNER, L. General Systems Theory Problems: perspective-practice. World Scientific Publishing Co., Singapore. 2005.

SLOVIC, P. The risk game. Journal of Hazardous Materials, v. 86, p. 17-24. 2001.

WILSON, J. Fundamentals of systems ergonomics/human factors. Applied Ergonomics, v. 45 , p. 5-13. 2014. 


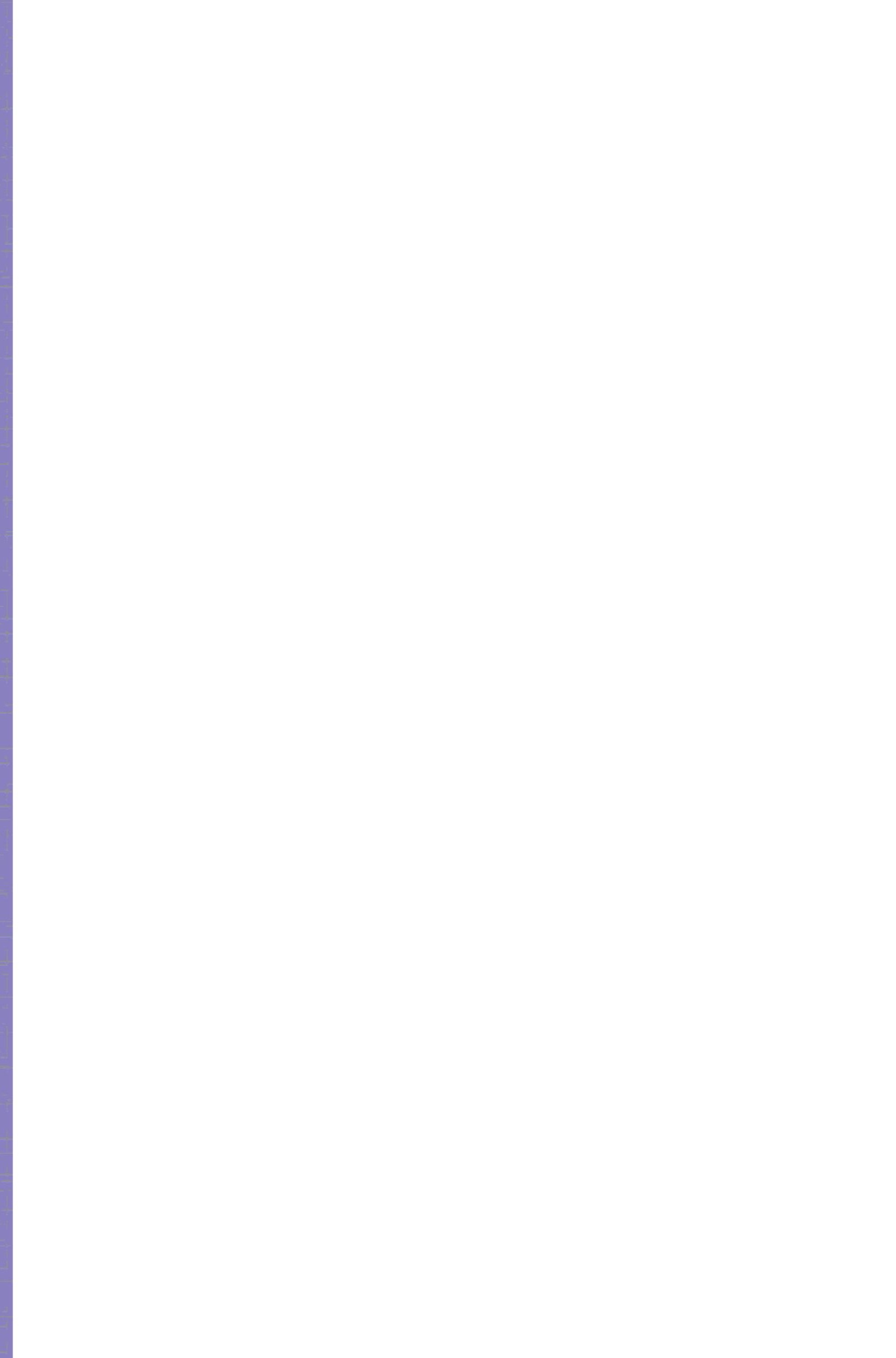

